\title{
Preparation and Characterization of a Bilayer Cr-C/Ni-P Coating on Aluminum 5052 as Bipolar Plates
}

\author{
Hsiang-Cheng Wang ${ }^{1}$, Hung-Hua Sheu ${ }^{2}$, Kung-Hsu Hou ${ }^{3, *}$, Shun-Yi Jian ${ }^{2}$, Ming-Hsien Lin ${ }^{2}$, \\ Ming-Der Ger, ${ }^{2, *}$ \\ ${ }^{1}$ Planning Division, National Chung-Shan Institute of Science \& Technology, Taoyuan 325, Taiwan \\ ${ }^{2}$ Department of Chemical \& Materials Engineering, Chung Cheng Institute of Technology, National \\ Defense University, Taoyuan 335, Taiwan \\ ${ }^{3}$ Department of Power Vehicle and Systems Engineering, Chung Cheng Institute of Technology, \\ National Defense University, Taoyuan 335, Taiwan \\ *E-mail: mingderger@gmail.com, khou@ndu.edu.tw
}

doi: $10.20964 / 2017.06 .81$

Received: 1 March 2017 / Accepted: 17 April 2017 / Published: 12 May 2017

\begin{abstract}
Aluminum alloy materials, with their light-weight and low-cost characteristics, are considered to be some of the most suitable materials for use as bipolar plates (BPPs). In this study, a chromiumcarbon/nickel-phosphorus (Cr-C/Ni-P) bilayer coating is deposited on aluminum alloy 5052 (AA5052) to improve the corrosion resistance and interfacial contact resistance. An electroless Ni-P layer is initially deposited on the AA5052 to form an undercoat, onto which a $\mathrm{Cr}$-C coating is subsequently deposited by electroplating from a trivalent chromium bath. The surface morphology and chemical composition of the prepared coatings were investigated using scanning electron microscopy (SEM) and electron probe X-ray micro-analyzer (EPMA) techniques. The surface morphology of the $\mathrm{Cr}-\mathrm{C}$ coating that formed with a plating time of $10 \mathrm{~min}$ is smooth and crack- and pinhole-free; however, cracks and pinholes are clearly observed in deposits that have been plated for a longer plating time. Therefore, the potentiodynamic test results indicate that the coating prepared at $10 \mathrm{~A} \mathrm{dm}^{-2}$ and $10 \mathrm{~min}$ possesses the best corrosion resistance $\left(i_{\text {corr }}=6.7 \times 10^{-7} \mathrm{~A} \mathrm{~cm}^{-2}\right)$. The contact resistance of the $\mathrm{Cr}-\mathrm{C}$ coating plated at $10 \mathrm{~min}$ is the lowest $\left(8.2 \mathrm{~m} \Omega \cdot \mathrm{cm}^{2}\right)$. The aluminum BPPs that have a $\mathrm{Cr}-\mathrm{C} / \mathrm{Ni}-\mathrm{P}$ bilayer coating exhibits great potential for PEMFC applications.
\end{abstract}

Keywords: Electroplating; Cr-C coating; Corrosion resistance; Aluminum bipolar plates; PEMFC

\section{FULL TEXT}

(C) 2017 The Authors. Published by ESG (www.electrochemsci.org). This article is an open access article distributed under the terms and conditions of the Creative Commons Attribution license (http://creativecommons.org/licenses/by/4.0/). 